\title{
OCCUPATIONAL HEALTH AND SAFETY: CHALLENGES AND PROSPECTS IN THE GREEK PUBLIC SECTOR
}

https://doi.org/10.47743/jopafl-2021-22-04

\author{
Georgios NASIOS \\ Panteion University of Social and Political Sciences \\ Athens, Greece \\ georgenasios@yahoo.com
}

\begin{abstract}
Occupational health and safety (OHS) is a major element of the labour relations aimed at protecting human life, preventing occupational accidents and diseases and protecting the health of the employees and the natural environment. OHS is an obligation of employers in the public and private sector in accordance with International Conventions, Directives of the European Union and provisions of the internal legal order. The article aims to present the most important challenges that employees in the Greek public sector face in the field of OHS, mainly through the study of the legal framework and the good practices of the public sector in other countries, as well as the comparison with those in force in the private sector. It also quotes initiatives that can be taken in order to prevent and improve the safety and health conditions of the employees, in the light of a complex economic, social, political and technological environment, where new occupational hazards are constantly emerging, as recently demonstrated by the spread of the COVID19 pandemic. In this way, the institutional framework of the OHS in the public sector can be aligned with the modern requirements and contribute to the improvement of the lives of the employees, the better provision of services to the citizens and the increasing efficiency of the public sector.
\end{abstract}

Keywords: Occupational health and safety, public sector, Greece

\section{Introduction}

Occupational health and safety (OHS) defines the obligation of the employer and at the same time the right and the obligation of the employee to comply with the implementation of the established health and safety regulations in the workplace, the working time and the way of working. OHS is an essential part of labour relations and is the objective of all parties with a view primarily to protect human life, as well as to prevent accidents at work and occupational diseases and to protect the health of the employees and the natural environment. In addition, there is an obligation for the employers in the public and the private sector to follow the rules deriving from International Conventions of the International Labour Organization (ILO), European Union (EU) Directives as well as legal provisions of the internal legal order (Kapetanidou, 2015). OHS is not just about employees and employers. On the contrary, achieving a safe and healthy environment is a key feature of social and economic prosperity and progress that can contribute to promoting economic growth and employment, by ensuring quality and productivity at work, and in a modern and prosperous society with fewer accidents, illnesses, health problems and deaths. Even on an individual level, the promotion and maintenance of high levels of OHS contributes to the reduction of accidents at work, occupational diseases and other health problems and ultimately promotes the social, mental and physical well-being and the well-being of each employee (Ministry of Labour and Social Affairs, n.d.). 
This article aims to identify the most important challenges that public sector employees in Greece face in the field of OHS, mainly through the study of the legal framework that governs it, as well as the comparison with the framework of the private sector and the good practices of the public sector of other countries. In this way, actions can be proposed to prevent and improve the health and safety of the employees, in the light of a complex environment in which new occupational hazards are constantly emerging, as recently proved by the spread of the COVID-19 pandemic. For this reason, the article focuses on the key issues about the OHS in the Greek public sector, such as its concept, its institutional framework, the framework of its strategy and policy, the emergence of its importance as a key part of the content of labour relations and the different levels of employment in the public sector about health and safety policy, taking into account differences in the framework of health and safety between the public and the private sector, good practices from other European countries and the risks emerging in the new employment environment, as shaped by rapid changes in the economic, social, political and technological environment.

\section{Occupational Health and Safety in the public sector}

\section{The concept of the Occupational Health and Safety}

OHS is defined as the science of predicting, evaluating and controlling risks that exist in the workplace and could harm the health and the well-being of the employees, taking into account the wider impacts on the environment. It is a key factor in achieving stable and decent working conditions and creating precautionary security policies. It is therefore a broad field that requires interdisciplinary analysis as many structures, knowledge and analytical skills are required to make sure the application of health and safety in the workplace (Alli, Benjamin, 2008). Protecting employees from illnesses, diseases and injuries has been a priority for more than a century, as set out in the ILO Preamble to the Constitution of 1919. Since then, the core of the ILO has been to achieve decent working conditions and to consolidate a precautionary culture about occupational health and safety policies, as shown by the adoption of the Convention on the promotion of occupational safety and health - article 187, as well as its accompanying Recommendation - article 197 (Ibid). Also, in the workplace there are reports of accidents at work, as a result of the lack of necessary health and safety conditions. An occupational accident is one that occurs during work or on the occasion of work, causes the employee unable to work and is due to a sudden event (Stamati \& Syriopoulos, 2013). According to the jurisprudence, an occupational accident is the accident caused due to a violent incident during the execution of the work of the victim (q.v. Decision 1415/2018 of Supreme Civil and Criminal Court of Greece), while according to the circular 45/24.6.2010 of the Hellenic Social Insurance Institute, it is defined as the death or the inability of the employee to work caused by a violent incident that occurred during the work or because of it (Ministry of Labour and Social Affairs, n.d).

\section{The framework of the OHS strategy and policy}

The promotion of OHS is a top priority for international, supranational and national organizations. At the core of the ILO activities is the investigation of the causes in order to reduce the incidence of occupational diseases and accidents at work and the prompting of 
an interdisciplinary approach to achieving this goal. In particular, at the EU level OHS is a key priority and is governed by the principle of the employer responsibility for work. This implies the legal and moral responsibility of the employers to ensure to all the employees (in any form / employment relationship) their health and safety through the implementation of the safety measures arising from the applicable legislation. The existing Community legislation has been adopted in accordance with the article 153 of the Treaty on the Functioning of the EU, according to which the EU has the power to issue instructions (directives) regarding health and safety at work. These directives - which are binding on the Member States in terms of their obligation to transpose them in their legal system - set out the minimum requirements and fundamental principles, such as the principle of risk prevention and assessment and the responsibilities of employers and employees, without precluding the adoption of stricter rules by the Member States. Furthermore, European guidelines and European standards (by European standardization bodies) can help the implementation of the directives mentioned above (Minister of Labour, Social Security and Social Solidarity, 2017).

An important directive in Community law is the Council Directive 89/391 EEC of 12 June 1989 (OHS Framework Directive), which guarantees minimum safety and health standards throughout Europe in the public and the private sector and is based on ILO Convention No. 155. Its basic principles concern prevention, occupational risk assessment, control and prevention measures, workplace awareness and consultation, employee participation and social dialogue. The European Social Charter of the Council of Europe also includes the enactment of regulations and measures related to the OHS and specific instructions on OHS concerning specific tasks and groups of employees or characteristics of the work (Ibid). Regarding the new European institutional framework, the European Commission recently announced the EU Strategic Framework for the OHS 2021-2027, following the Strategic Framework of the EU for the OHS 2014-2020, in view of the significant changes in the environment, the new technologies, the demographic composition of the population and the health crises, with the aim of predicting and managing as much as possible the changes in the new working landscape that is being formed (European Commission, 2021). Greece, as a Member State of the strong core of the EU, has adapted to the requirements of the Community law and therefore its strategy and individual policies have been harmonized with the European framework. It also participates in the process of reporting on the implementation of the Directives and monitors through the Advisory Committee for the OHS the progress of the relevant procedures. However, there is significant room for autonomous strategy and policy, as evidenced by the formulation of a National Strategy for Health and Safety, which was last approved for the years 2016-2020. This Strategy states that there is a sufficient degree of flexibility in the development and management of policies for OHS at the national level and more specifically in the existing structures for OHS (national legislation, national authorities, control mechanisms, national tripartite bodies, structures responsible for information, awareness raising, education and training, research, data collection and statistical processing and networking and development of collaborations). Reference is also made to the role of the social partners, the consultation, the monitoring of the implementation of the legislation, the protection and prevention services, the high-risk activities, the challenges of the current national situation, while also the national strategic planning in vision, strategic goals, priority areas, funding, monitoring, evaluation and 
disclosure is specialized. An explicit reference is made to the sparse production of legislation by the national law, as it derives from the Community legislation, and to the limited possibilities for "domestic" legislation (Minister of Labour, Social Security and Social Solidarity, 2017).

At the national level, the formulation of the strategy and policy for the OHS is carried out by the Ministry of Labour and Social Affairs (by the Directorate for the Occupational Health and Safety and the National Focal Point of the European Organization EU-OSHA). An important role is also played by the Occupational Health and Safety Inspectorate of the Labour Inspectorate Body, the Employees' Health and Safety Council, the Social Audit Board of the Labour Inspectorate Body, the Advisory Committee for the issuance of a certificate of legal assistance to External Protection and Prevention Services and the Employees' Health and Safety Committees (ibid). Crucial is also the government funding to cover OHS-related operating costs, especially in the public sector, such as equipment and staff training. In recent years, there has been a significant reduction in this funding, which significantly affects the content of the work of the employees of the public sector and weakens and degrades their capabilities and role (Koinoniko Polykentro of ADEDY, 2013). The funding includes also the wage policy of the government regarding the provision of allowances and benefits that can be granted to the employees of the public sector and in particular the amount of the allowance for hazardous and unhealthy work and the specialties of the eligible employees in accordance with the provisions of Law 4354/2015. It is noted that the previous Law 3205/2003 provided the allowance for dangerous and unhealthy work and also the granting of an extra employment allowance, an allowance of special working conditions, an allowance of high degree of responsibility and safety, a special allowance for penitentiary and correctional facilities, a special allowance for radioactivity, clothing allowance, etc.

In any case, the role of the international and supranational organizations that influence national OHS policies and strategies is not insignificant. For example, European standardization bodies, the European Committee for Standardization, the European Commission for Electrotechnical Standardization and the European Telecommunications Standardization Institute aim to ensure a high level of health and safety protection (European Agency for Safety and Health at Work, n.d), and the ILO seeks to ensure that high priority is given to OHS in national agendas and policies, especially regarding the development and maintenance of a preventive culture and the implementation of a system management approach in OHS. The main tool used in this direction is the issuance of international work standards, codes of good practice and guidelines (Alli Benjamin, 2008; International Labour Organization, 2015).

\section{The institutional framework of the OHS in the Greek public sector}

The basic rule of law that regulates the issues of health and safety of the employees is Law 3850/2010. The above Law applies to all companies and operations of the private and the public sector. It is actually a code of laws, which has been ratified according to the article $76 \S 7$ of the Constitution of Greece, that codifies all the provisions in force for the health and safety of the employees. The Law contains general provisions (scope, definitions), the tools for the improvement of the working conditions at the national level, the building requirements, the prevention of occupational risk, the protection of the 
employees from physical, chemical and biological agents, the obligations of employers and employees, the protection of minors at work and the penalties imposed. Specifically, for the public sector the issuance of Presidential Decrees on health and safety issues is provided (ref. article $2 \S 6$ ), while reference is made to more specific health and safety issues (e.g. article $4 \S 6$ for the appeal to a decision of a labour inspector, article 44 for the allowance for dangerous and unhealthy work and granting items of personal protection in dangerous or unhealthy occupations or places and article 69 for the cooperation of public services related to the health and safety of the employees). It is worth noting that the guarantee of health and safety conditions at work had been already provided by the provisions of Law 1568/1985 (with special provisions for the public sector).

Furthermore, according to Law 3528/2007 and Law 3584/2007, which are the main pillars of law for the employees in the public sector and concern the ratification of the Code of Civil Servants and Employees of Public Entities and the Code of Municipal and Community Employees respectively, it is explicitly stated that the employees have the right to ensure health and safety conditions in their workplace, which is specified either by Presidential Decree or by special provisions regarding the supervision and control of compliance with health conditions and security. Also, the OHS in the public sector has constitutional foundations, as it results from the provisions of the article $22 \S 3$ of the Constitution of Greece (concerning individual and social rights and labour protection) which states that the Law defines what is valid for the collective labour agreements for the civil servants, the employees of local authorities and the employees of public entities. This Law (2738/1999) stipulates that the trade unions of the employees mentioned above negotiate, among others, the terms and conditions of the OHS (ref. article 3).

More specific provisions for the OHS in the public sector are provided in other rules of law, most important of which are Presidential Decree 157/1992, Law 2224/1994, $\Phi 10221 /$ oıк.26816/929/30-11-2011 Decision of the Minister of Labour \& Social Security and Laws 4483/2017 and 4484/2017, that concern issues such as personal protective equipment for the health and safety of the employees, allowance for dangerous and unhealthy work and benefits to ensure the health and safety of working conditions. Also, provisions related to the OHS exist for more specific categories of employees of the public sector, such as Presidential Decree 45/2008 for hygiene and safety measures of the uniformed personnel of the Hellenic Police, Presidential Decree 289/1986 for the health and safety of the employees in areas supervised by the Ministry of National Defence, Law 1284/1982 for the allowance of civil and military servants with quadriplegia and paraplegia and Presidential Decree 305/1996 regarding the safety and health specifications at the construction sites (that also concern public works).

It is noted that all relevant European directives and recommendations on OHS have been incorporated into the national legal framework. However, shortages of qualified scientific staff and the understaffing of control mechanisms lead to an improper implementation and sometimes to the annulment of the formal legislative framework in practice. It has also been argued that the institutional framework is actually non-existent, fragmented and inadequate with understaffed structures (Minister of Labour, Social Security and Social Solidarity, 2017). 


\section{OHS as a key content of labour relations}

\section{The importance of OHS}

The protection of OHS undoubtedly contributes to the achievement of a healthy and safe working environment and to economic growth and employment, as it ensures productivity and quality at work. However, a wider social and economic prosperity and a prosperous state can be achieved, as unpleasant events are prevented, such as the deaths of employees from accidents at work and the occupational diseases. Also, the financial cost is significantly reduced, if we take into account that according to the ILO the total cost of accidents at work and occupational diseases amounts to about 4\% of GDP, while according to EU-OSHA, the cost to the EU economy from occupational diseases and accidents at work is estimated at 490 billion euros per year. These costs hinder economic growth and negatively affect the productivity and competitiveness of businesses, while at the same time the social security and health care systems are burdened, resulting in a burden of the state budget and the citizens. For this reason, ensuring satisfactory working conditions contributes to the quality of life of employees, to the competitiveness and productivity of businesses and to the reduction of costs for the economy. That is, it benefits citizens, employees, businesses and society (ibid).

\section{The effects of OHS on key variables of work behaviour}

Ensuring satisfactory health and safety conditions is beneficial for the employees, the employers, the public sector, the society and the economy. In the case of employers in particular, the prevention and protection of employees from the risks arising from the working environment is a matter of high priority. Indeed, many injuries occur in the workplace, while a significant number of employees suffer from work-related illnesses, with the majority of them coming from work-related stress and musculoskeletal disorders. For this reason, the public sector and the employers are trying to settle the safety and health issues that exist in their facilities through the provision of training, the reduction of work stress levels and the improvement of health and safety standards and control mechanisms (Health and Safety Executive, n,d). Many employers view health and safety issues as an additional cost and not a profitable investment and in several countries there have been a reduction in public spending on OHS inspections. However, a further analysis of the importance of occupational health and safety conditions shows that their effects can be positive, both for the employers and the employees. More specifically, EU-OSHA focuses on the consequences of work stress resulting from the lack of the necessary safety and health conditions. At the employer level, the consequences include absenteeism, errors in the employee performance, deviation from the work schedule, discipline problems, harassment, reduced performance in tasks, accidents, mistakes and increased costs due to the payment of expenses or medical care. At the employee level, work stress can result in emotional reactions (such as irritability, sleep problems, depression, alienation, exhaustion, family problems), cognitive reactions (difficulty in concentrating, memory, learning new things and making decisions), behavioural reactions (drug abuse, alcohol, smoking), physical reactions (back pain, weakened immune system, peptic ulcer, heart problems, hypertension) and psychosocial risks (such as job insecurity) associated with symptoms such as high alcohol consumption, obesity, lack of exercise, increased smoking and sleep disorders (European Confederation of Independent Trade Unions, 2017). 
The ILO's view on synergies between security and productivity is moving in the same direction. More specifically, taking measures to prevent illnesses and accidents at work leads to improved productivity, reduced staff absenteeism, reduced compensation and insurance costs and better facility maintenance, better mental health of employees (resulting in higher morale and better concentration at work), reduction to a large extent of problems related to the suspension of work, as well as better image and reputation of the employer through the improvement of the relations with traders. At the same time, accidents at work and occupational diseases have adverse consequences for employers, such as: absences of employees, reduced productivity, malfunction in services provided, costs of compensation, rehabilitation and care of employees, increase of insurance premiums, legal proceedings and investigations by the authorities, recruitment of new staff to replace absent staff and their retraining, as well as drop in staff morale and tendency to leave work (International Labour Office, 2006).

In addition, according to the Secretariat of health and safety of the Greek Civil Servants' Confederation, it is proved after ergonomic studies that there is a direct relationship between working conditions and performance of the employees, as well as certain health problems (mainly musculoskeletal). Working conditions include the configuration of the seat and the desk, the lighting, the temperature, the ventilation and air quality, the spatial planning and the fire risk forecasting (Soumeli, 1998). In this regard, the most favourable employment conditions for employees of the public sector, resulting mainly from better health and safety conditions (such as adequate cleanliness) and the ability to focus on the core of their activities, leads to increased productivity and efficiency of public sector bodies ("Explanatory Memorandum on Law on Social and solidarity economy and development of its institutions and other provisions”, 2016; Hellenic Parliament, 2016).

\section{The adoption of "multi-speed" labour relations in the public sector in relation to the OHS}

Flexible forms of employment have prevailed internationally in the labour market. They are those forms where a factor deviates from those applicable to the standard dependent work (or salaried dependent work), such as the duration of the contract, the working hours or the workplace. Especially in the public sector, flexible forms of employment are those in which the employment relationship differs from the relationship under public law (at the core of which is the tenure) by which civil servants are governed. The main forms of flexible employment in the public sector are private law employment contracts of indefinite and fixed duration, part-time employment, project leases, occasional staff, outsourcing, independent service contracts and remunerated mandate. Flexible forms of employment have been institutionalized in the public sector for several years, but in recent years they have been used more and more in a range of activities. The reasons for the increase are due to the rapid changes in the economic, social and technological environment, the directions and guidelines of European employment policies, the promotion of social policy and the immediate needs of the public sector, while the consequences of their implementation concern the economy, the society, the labour market, the operation of public services and civil servants and, in particular, the labour relations in the public sector. According to the data of the Register of Human Resources of the Greek 
State, the non-permanent employees in the public sector constitute a large percentage of the total number of employees and are classified in many categories, resulting in many categories of employment in the public sector. As a result, the legal framework has been adapted to include rules of law governing labour relations for these groups of employees as well (Nasios, 2020a; Nasios, 2020b).

Therefore, the possibility of legal and regulatory coverage of these forms of employment remains relevant, where the concepts of employer, employee and workplace are not "clear" in the range of the content of labour relations and of the OHS (Minister of Labour, Social Security and Social Solidarity, 2017). It has also been reported that employees with flexible forms have increased stress and feel job insecurity, due to their uncertainty about their future at work as well as reduced job opportunities and reduced financial stability, with negative consequences for their mental well-being and health. In addition, many employees with flexible forms perform hazardous work with poor working conditions and minimal training in the OHS and have a high risk of injury and work longer hours than scheduled, with a negative impact on the balance between personal and professional life (European Confederation of Independent Trade Unions, 2017). It is also worth noting that significant violations of insurance and labour laws and abuses of working conditions have been reported, especially in the case of outsourcing (through the public procurement process) on issues such as social security, working hours, payroll, trade union freedom, OHS, abusive working conditions, as well as inferior labour content, adverse changes in working conditions, blackmail, "cloning” of employees and dismissals, as well as confrontations between the public sector employees and the contractors (Hellenic Parliament, 2011; INE-GSEE/ADEDY Labour Institute, 2009; Ministry of Health, 2016; Ministry of Labour, Social Security and Welfare, 2014; The Greek Ombudsman, 2012).

Of course, it applies in general that all employees in the public sector have the right to ensure OHS conditions. For example, the public bodies where the employees of the special employment programs for the unemployed, the public benefit programs and internship are employed, are obliged to ensure the level of protection provided to all the employees according to the provisions of Law 3850/2010 as well as more specific provisions and provide the necessary guidance on the risks associated with OHS (Greek Manpower Employment Organization, 2018. See also article 1 of Law 4368/2016). Indicative regulations that can be mentioned is the article 22 of Law 4368/2016 and the oıк.2/16519/0022/24-02-2012 Joint Ministerial Decision concerning the granting of allowance for dangerous and unhealthy work for permanent employees and employees of indefinite and fixed term under private law of the bodies engaged in the storage and treatment of solid waste, the Presidential Decree 398/1994 concerning the minimum safety and health requirements when working with visual displays and the 55932/1016/02-122016 Joint Ministerial Decision concerning the granting of allowance for dangerous and unhealthy work in case of employment in specific host institutions, such as the National Organization for Medicines (Greek Manpower Employment Organization, 2018. You can also see articles 97 and 98 of Law 4483/2017 regarding personal protective equipment related to the health and safety of employees and payment of allowance for dangerous and unhealthy work for employees with fixed-term employment contracts and project lease). It is worth noting that the European Labour Authority and the European Commission draw attention to the need to promote fair and safe working conditions, especially for seasonal employees (European Commission, 2021). However, there are cases where the allowances 
are not paid, such as for those employed under a contract of employment, although the payment of the unhealthy work allowance is provided for the civil servants for the same job, while in some cases of flexible forms of employment the Article 662 of the Civil Code on the safety and hygiene of the workplace applies (Ministry of Health, 2016).

Finally, it is worth mentioning that the employment of people with flexible forms in the public sector also contributes to the provision of health and safety conditions (e.g. cleaning, security). This results in more favorable employment conditions for all employees and better health and safety conditions, with the end result of the increased productivity and efficiency of employees due to the focus on the core of their activities and the immediate filling of gaps arising from understaffing and the restriction on the recruitment of employees, due to restrictive budgetary conditions (Hellenic Parliament, 2016).

The OHS framework in the public sector: Substantial differences from the private sector

It is explicitly stated in the approval of the National Strategy for OHS for the years 2016-2020 by the Ministry of Labour, Social Security and Social Solidarity that in the Greek public sector the legislation for occupational health and safety is ignored (except for the Municipalities and the Public Enterprises and Organizations). However, as mentioned above, there is a relevant institutional framework, so such a finding leads us to the conclusion that obviously the rules of law do not apply in practice. More specifically, the National Strategy states that both the Ministry of Labour and almost all the Ministries do not have any infrastructure for their employees about the provision of OHS services. On the contrary, the situation in the private sector seems to have improved, where the provision of health and safety services to employees is described even as formal and substandard (especially in very small and small enterprises). The main reason is the fulfillment of the legal obligations deriving from the provisions that have established Committees for OHS at the company level, the existence of protection and prevention services (external / internal), the classification of companies in different risk categories, the adequate supervision and training of employees, the recruitment of safety technicians and occupational physicians, Council for OHS at the national level, Prefectural and Special Committees for OHS (e.g. in shipyards), the general building requirements, the protection of employees from physical, chemical and biological agents and fire protection and from the employers' obligations on issues such as risk assessment, consultation and social dialogue. Although the implementation of the legislative framework for OHS in the private sector is characterized as incomplete, its existence cannot be ignored, in relation to those in force in the public sector (Minister of Labour, Social Security and Social Solidarity, 2017).

From the institutional framework that is applicable in the private sector about the OHS and its implementation to date, there is a possibility of active participation of employees and consultation with employers, as well as an enumeration of the obligations of employers (Kapetanidou, 2015). At the same time, the content of general and specific collective labour agreements concerning the private sector that set minimum working conditions, wages and salaries and contain mandatory institutional (non-wage) regulations, includes issues related to health and safety ("General Collective Bargaining Agreement in 
the State”, 2000) while in the case of dispute resolution the possibility of using mediation and arbitration services is provided (such as the Organization for Mediation and Arbitration). It should be noted that in the private sector, albeit to a lesser extent, the relevant labour legislation concerning the OHS is implemented, assisted by the adoption of preventive measures and individual and collective protection measures, the existence of an Employee Health and Safety Council, conducting seminars on health and safety issues, the consultation between employees and employers, the activation of control mechanisms (mainly of the Safety and Health Inspection Services of the Labour Inspectorate Body) and of the Social Control Council of Labor Inspection and the activity of External Protection and Prevention Services (Minister of Labour, Social Security and Social Solidarity, 2017), while in some cases special health and safety provisions are provided for certain specialties (e.g. Presidential Decree 70/1990 regarding the health and safety of shipbuilding workers) or in heavy and unhealthy jobs (see for example article 27 of Law 4618/2019).

On the other hand, in the public sector there is no single enforcement and sanction mechanism for workplace health and safety issues, although there is supervision by senior public authorities. Also, administrative sanctions and certification and collection of fines do not apply to the State and Legal Entities under Public Law. This "gap" seems to be filled by the trade unions, mainly through the promotion of safety and hygiene issues (Kapetanidou, 2015; Lampousaki, 2013; Supreme Administration of Civil Servants' TradeUnions, 2018). It can therefore be argued that the public sector lags behind the private sector in terms of health and safety. This backlog of the public sector is not only a Greek phenomenon, as it is observed in other countries as well, such as in the United Kingdom, mainly in the areas of prioritization of health and safety, invested time and resources, training of employees, adoption of best practices and compliance with standards, as well as conducting health and safety inspections (Safety \& Health Practitioner, 2018). Therefore, the establishment of a working group in the Ministry of Labour and Social Affairs for the implementation of the institutional framework on OHS in the public sector is in the right direction with the aim of drawing up a medium and long term plan to mitigate of the factors of dangerous and unhealthy work in the public sector and the establishment and consolidation of the necessary conditions for the prevention and protection of the employees (Ministry of Labour and Social Affairs, 2020).

\section{Emerging risks and challenges in OHS in the public sector}

Globalization and the wider social, technological, economic and political changes have significantly affected the labour sector and the OHS. More specifically, the liberalization of world trade, changes in communication and transport technologies, demographic changes, population movements and the size, structure and life cycle of enterprises have resulted in the introduction of new practices and employment standards which in turn have created new types of risks with regard to OHS (Alli Benjamin, 2008). The public sector is traditionally considered a low-risk work environment, but many frontline services face challenges in managing OHS issues. Of course, the "traditional" dangers in the outdoor and indoor areas of the workplace still exist. The prevention of these risks requires the adoption of measures and practices, such as: adequacy of building facilities and technological infrastructure, facilitating access for ambulances and fire trucks in emergencies, emergency response information, emergency care, use and storage of 
flammable and hazardous substances and management / destruction of toxic and hazardous waste in an appropriate way, training of personnel in the use of machinery in accordance with safety rules, compliance with the rules for prohibition of hazardous work and frequent inspection of workplaces for health and security (Kapetanidou, 2015).

In addition, risks related to working conditions arise from the widespread use of computers, mainly in office spaces (lighting, ergonomics), the non-systematic treatment of safety and hygiene problems of employees in workplaces of high risk (such as garbage collection, shipbuilding and repairs at the Ministry of National Defence), as well as the improper treatment of accidents at work and occupational diseases and the non-provision for special treatment of employees in case of relevant events, which are treated more as common diseases and are not recorded as accidents at work and illnesses ("Seven Challenges for the Future of Occupational Safety and Health”, 2010).

However, the rapid changes that are taking place in the world at the social and political environment do not leave unaffected the sector of the OHS, which faces challenges that are characterized as complex and difficult to solve (Soumeli, 1998). An important issue arises from the increasing use of flexible forms of employment and flexible forms of work organization in the public sector (such as self-employment, temporary employment, contracting, hiring) and more specifically from the legal and regulatory coverage of these forms of employment in OHS issues, where the concepts of employer, employee and workplace need updating. Furthermore, information and communication technologies are increasingly used in public services and have revolutionized every aspect of work. Examples that can be cited include the ability to improve employee productivity, the increased workload, longer working hours and fragmented leisure time, resulting in the difficulty of finding the right balance of family and working life (European Confederation of Independent Trade Unions, 2017; Minister of Labour, Social Security and Social Solidarity, 2017).

Also, the adoption of New Public Management in recent years in the public sector of European countries has changed the working conditions of the employees of the public sector in terms of increasing their pressure to improve efficiency. This is facilitated by the copying of practices from the private sector, such as results management models, decentralization of activities, introduction of financial control systems and the gradual "transformation" of the public sector as an entity that buys and sells services in a free market. Furthermore, the reduction of trade union density and employee representation seems to reinforce the reduction of resources available in the public sector and in the OHS (Schmidt et al., 2017).

In addition, the recent Covid-19 pandemic has exacerbated the dangers in the working environment and points out that the challenges of OHS remain and are difficult to forecast. Also, the green and digital transition and the large business investments have changed the nature of work, the work patterns and the workplaces. New occupations and jobs have emerged, work flexibility is enhanced, the place and time of work is becoming more and more irregular, the workforce is aging (especially in Europe), new opportunities are presented to employees of all ages due to advances in technology, new tools and machinery (with increasing use of digitization), robotics, artificial intelligence and teleworking are used (resulting in reduction of hazards in workplace) and the intensifying climate change has affected work in terms of rising ambient temperature, air pollution and extreme weather events. The use of equipment with visual and recording screens as well 
as the remote work with the use of wireless, mobile and other advanced technologies and digital platforms are also becoming more frequent. These developments raise issues related to the safety and health of employees due to their exposure to electromagnetic fields, optical radiation and high power electronic devices (European Agency for Safety and Health at Work, n.d.; European Commission, 2021).

Further analysis is also needed for the psychosocial risks and mental health problems that emerged during the pandemic period and the increasing use of teleworking, with particularly negative effects on stress and self-esteem. Teleworking has blurred the boundaries of private and professional life, while the constant connectivity, the intensification of work, the discouragement of union membership and their activism related to problems at work, the unclear description of employers' obligations to provide the necessary equipment, the non-use of the right to disconnect in practice, the social alienation and the lack of social contacts lead to increased ergonomic and psychosocial risks. Furthermore, in recent years there have been phenomena of labour exploitation, as well as violence, harassment and discrimination in the workplace based on gender, racial or ethnic origin, religious beliefs and sexual orientation. At the same time, employment during the pandemic poses risks of its spread and for this reason measures have been adopted and tools and equipment (personal protective equipment) have been used to reduce risks, especially the risk of transmitting infectious diseases (European Commission, 2021; Godderis \& Luyten, 2020). In the Greek public sector, the Ministry of Interior issues weekly circulars from the beginning of the pandemic that apply to all facilities and concern OHS measures, such as keeping distances, avoiding congestion, providing protection materials in all areas, ensuring regular disinfection and ventilation of the premises, restrictions on the use of the elevators, record keeping of Covid-19 patients, mandatory use of personal protective equipment, serving citizens with technological or telecommunication means, electronic conferences, special permits for the staff, special care for vulnerable groups, diagnostic tests, compliance with vaccination obligation and suspension of duties (See analytically Ministry of Interior, n.d).

However, it is obvious from a systematic review of the literature on the OHS that challenges also arise from the climate change and the sustainable development and responsibility, which will affect all sectors of activity. Also, other challenges arise in certain activities, such as heat stress, noise exposure, chemicals and radiation, fatigue, musculoskeletal disorders, increased psychosocial load, ergonomic issues and unexpected accidents and injuries. There is also a great deal of uncertainty as to what will emerge from the ongoing fourth industrial revolution that brings together the convergence of innovative technologies such as autonomous robots, nanotechnology, artificial intelligence and the Internet of Things. Also, increased computer work will increase musculoskeletal disorders and will change the content, management and organization of work in general and will create the need to accelerate the pace of work and the need for continuous learning, extensive know-how and continuous self-development, use of digital tools to monitor the employee performance as well as the need to take more responsibility and engage in complex human-machine interactions to prevent remote attacks (Lindholm et al., 2020). 


\section{Good practices in OHS from the European public sector}

It is worth mentioning the practices concerning the safeguarding of OHS applied in the public sector of other European countries, to encourage the study of their possible application in the Greek public sector. To illustrate some cases, we can cite the case of the United Kingdom, where the Government Health and Safety Executive (HSE) has a key role to play in reducing work-related stress and work-related deaths and injuries. The HSE collaborates with all stakeholders to improve OHS with the strategic goal of providing guidance and direction to health and social care providers on managing incidents of violence and aggression in the workplace, building and maintaining a collaborative network to improve understanding of the role of HSE, applying stress management standards (through pilot exercises) to certain facilities (e.g. education, prisons, defence, health) and small public sector entities that lack resources and know-how, developing personalized solutions, identifying and managing risks, establishing control measures of health and safety performance, conducting inspections and supporting the development of the management capacity of the entities (Health and Safety Executive, n.d.). In addition, several public bodies in Sweden with insufficient capacity to manage health and safety issues use external support services from OHS service providers (Schmidt et al., 2017). The Spanish public sector has also adopted a management system for the prevention of occupational hazards, through a limited risk assessment methodology, which contains a checklist of risk factors, the Belgian public sector has developed a policy aimed at preventing customs officials from taking risks during container inspections, which clearly outlines the technical standards and requirements for carrying out their work and German public sector has developed a tool for assessing the risks arising from mental stress, with a combination of questionnaires and discussions aimed at continuous improvement (European Confederation of Independent Trade Unions, 2017).

In each case, every country has different sociological, institutional and economic structures, which affect the productive activity and the management of the OHS. Particularly in the public sector, which has significant political and institutional differences from country to country, there is a different organization of services and a different way of working, resulting in different types of occupational risks (ibid). In any case, the study of the basic principles of the OHS by the ILO can be extremely interesting. The Organization has studied in depth the issues of OHS and has issued Recommendations and Codes of Practice that incorporate the necessary principles, provisions and technical instructions for the creation, implementation and management of OHS systems, which can be useful to those who design the relevant policy (e.g. governments, employers' and employees' organizations) and those practically involved in implementing measures to promote and protect the safety and health of employees, such as managers, supervisors, employees' representatives and labour inspectors (Alli Benjamin, 2008; International Labour Organization, 2015).

\section{Conclusions and policy proposals}

It follows from the above that OHS is a key part of labour relations and has significant implications for fundamental variables of the labour behaviour. This is particularly important in the public sector, which plays an essential role in society and the 
economy, and the increase of its efficiency and productivity has been a demand of all governments in recent years. OHS can increase the efficiency of the employees and the services and reduce the costs of poor compliance with health and safety rules. However, the existing institutional framework needs to be updated and improved in order to achieve the desired OHS conditions in an ever-changing economic, social and technological environment with emerging risks, challenges and opportunities and in a public sector that competes with the private sector in the provision of services and is distinguished by an increase in "working speeds", in addition to the public law relationship governed by the civil servants. Many steps can be taken to align the institutional framework in the public sector with the modern requirements and to contribute to improving the lives of employees, providing better services to citizens and increasing its efficiency. International and supranational organizations, research institutes, good practices from other countries, research studies and strategy and policy proposals from institutional and non-institutional bodies can contribute to addressing the challenges ahead and improving the health and safety of the public sector employees. Also, in addition to the will that must exist in each government to improve the health and safety conditions, there is the obligation to harmonize national law with the requirements of the EU law on working conditions in the public sector.

The ILO has several tools that can be used in a national context, such as international labour standards, codes of practice, technical advice and dissemination of information, which in some cases are binding, as well as guidelines with scientific documentation. All of the above contribute to the broad involvement of the social partners, to the emphasis on prevention and protection, to the continuous improvement of rules, to the dissemination of information and training of employees on health and safety issues, to the compensation, rehabilitation and treatment services of employees in accidents and to the continuous monitoring and inspection of OHS systems. The European Commission has also set out to anticipate and manage change in the new world of work as it emerges from the green, digital and demographic transition and changes in industries, equipment and workplaces, to improve accident and disease prevention in the workplace and increase preparedness for possible health crises, which include psychosocial risks, through enhanced documentation, social dialogue, adequate funding, awareness raising and close cooperation with EU countries, regional and international organizations and international forums (European Commission, 2021). These organizations also point to the dangers posed by technological development and cybersecurity, increased chemical use, climate change and sustainability, and recommend focusing on employee well-being as psychosocial risks increase (Lindholm et al., 2020).

The Supreme Administration of Greek Civil Servants Trade Unions suggests that the configuration of workplaces take into account the proper specifications according to ergonomic studies (in matters such as lighting, temperature, seat configuration, ventilation, spatial planning, fire safety), that there should be adequate information and training for employees on eliminating and avoiding risks at work, to reconsider the granting of the allowance for dangerous and unhealthy work, the provision of financial incentives and more favourable insurance and pension arrangements and the reduction of working hours in places of increased risk, to clearly delineate the concept of accident at work and occupational disease in the Civil Service Code, to record accidents and illnesses in order to rank interventions and control the performance of risk reduction measures and the 
existence of an occupational physician and security technician in public services. It should be mentioned that an empowered trade union movement functions as a key pillar of the legal protection of the employees (Soumeli, 1998). Also, according to the Ministry of Labour \& Social Affairs, the legislation should be implemented, an Internal Protection and Prevention Service (or organized internal structure) should be set up in public services, the use of occupational physicians and safety technicians should be increased, health and safety committees should be activated and prevention in the workplace in general should be increased. It also proposes the creation of a National OHS System that will produce policies, legislation and operating rules, establish support structures and activate control mechanisms as well as the development of information systems for the export of reliable, up-to-date and comparable statistics, following a clearly defined process of identification, recording and reporting of accidents and diseases. It is also necessary to increase the coordination between the co-competent Ministries and bodies regarding the OHS in addressing new and emerging occupational risks and to review, simplify and codify the legal framework with emphasis on addressing challenges, upgrading and promoting health and safety conditions and re-evaluating sanctions, as well as increasing funding and introducing health and safety compliance mechanisms in line with the views of scientific and social actors, whose role needs to be strengthened. In any case, at the core of the management of OHS issues by the Ministry of Labour \& Social Affairs is the application of general principles of prevention in line with the European approach, the assessment of occupational risks and the awareness and consultation in the workplace with enhanced importance of social dialogue (Minister of Labour, Social Security and Social Solidarity, 2017; Ministry of Labour and Social Affairs, n.d).

It is worth noting that the rapid changes taking place in all sectors - which are not easy to identify - need public sector vigilance regarding the possible cause of accidents at work and occupational diseases and quick reflexes in dealing with them. This may require constant updating of all actors and the enactment of new laws to protect the health and safety of the employees. An example of this is the Covid-19 pandemic, where for the public sector employees, specialized prevention measures were rapidly legislated (in the form of Acts of Legislative Content) and circular instructions are provided on a weekly basis, while at the same time the framework of teleworking in the public sector was institutionalized (Law 4807/2021), following the extraordinary institutional framework during the pandemic period, where the obligations of employers and employees are more clearly defined (Ministry of Interior, n.d.). Also, many countries that implement strategies to exit the pandemic are preparing to deal with the possible consequences of the threatening global economic downturn, the negative economic growth and its impact on employment, as well as with the consequent health problems of the employees and the allocation of resources for the health and safety of the employees. At the same time, they use the know-how they have acquired in maintaining security measures during the pandemic, in order to create more attractive and safer jobs (Godderis \& Luyten, 2020). Finally, the social partners can make a valuable contribution to the creation of a safe and healthy working environment, such as the Hellenic Institute of Occupational Health and Safety, which undertakes actions and initiatives in research, information, consulting and education to create a safe and healthy working environment as well as the trade union civil service movement as a key pillar of ensuring the right to health and safety at work (Koinoniko Polykentro of ADEDY, 2012). 


\section{References}

1. Alli Benjamin, O. (2008). Fundamental principles of occupational health and safety. Geneva: International Labour Office.

2. European Agency for Safety and Health at Work (n.d.). European Standards. Retrieved from https://osha.europa.eu/el/safety-and-health-legislation/standards.

3. European Commission (2021). EU strategic framework on health and safety at work 2021-2017. Occupational safety and health in a changing world of work. Retrieved from: https://eur-lex.europa.eu/legalcontent/EN/TXT/?uri=CELEX\%3A52021DC0323.

4. European Confederation of Independent Trade Unions (2017). Health and safety at work in the public sector in Europe: New challenges. Retrieved from https://www.cesi.org/wpcontent/uploads/2016/06/ADAPT-Study-for-CESI_2016-EN-web.pdf.

5. "Explanatory Memorandum on Law on Social and solidarity economy and development of its institutions and other provisions” (2016). Retrieved from https://www.hellenicparliament.gr/UserFiles/2f026f42-950c-4efc-b950-340c4fb76a24/k-alan-eis-

synolo.pdf [in Greek].

6. "General Collective Bargaining Agreement in the State” (2000). Enimerosi, 61-62, 2-11 [in Greek].

7. Godderis, L. \& Luyten J. (2020). Challenges and opportunities for occupational health and safety after the COVID-19 lockdowns. Occupational and environmental medicine, 77, 511-512. http://dx.doi.org/10.1136/oemed-2020-106645

8. Greek Manpower Employment Organization (2018). Public Invitation No 11/2018. Retrieved from https:/diavgeia.gov.gr/doc/7\%CE\%9C\%CE\%9B34691\%CE\%A92-

\%СЕ\%9B\%СE\%9F\%СE\%92?inline=true [in Greek].

9. Health and Safety Executive (n.d.). Sector plan for health and safety: Public services. Retrieved from https://www.hse.gov.uk/aboutus/strategiesandplans/sector-plans/public-services.pdf.

10. Hellenic Parliament (2011). Question No. 18716/01-07-2011 to the Ministers of Culture \& Tourism, Finance and Infrastructure, Transport \& $\quad$ Networks. Retrieved from https://www.hellenicparliament.gr/UserFiles/c0d5184d-7550-4265-8e0b-078e1bc7375a/7425089.pdf [in Greek]

11. Hellenic Parliament (2016). Question No. 2177/04-01-2016 to the Minister of Interior \& Administrative Reconstruction. Retrieved from https://www.hellenicparliament.gr/UserFiles/c0d5184d7550-4265-8e0b-078e1bc7375a/9439490.pdf [in Greek].

12. Howard, J. (2010). Seven challenges for the future of occupational safety and health. J Occup Environ Hyg, 7(4), D11-D18.

13. Iacobuţă, Andreea-Oana; Asandului, Mircea; Gavrilovici, Cristina; Oprea, Liviu Regional analysis of inequalities in Romanian healthcare system. Social Research Reports, 2013, Vol.23, 7-18.

14. INE-GSEE/ADEDY Labour Institute (2009). Labour relations in the cleaning industry. Results of empirical research. Athens: INE-GSEE/ADEDY Labour Institute [in Greek]. Retrieved from https://www.inegsee.gr/wp-

content/uploads/2014/02/files/ERGASIAKES\%20SXESEIS\%20STON\%20KLADO\%20KATHARISMOU .pdf.

15. International Labour Office (2006). Occupational safety and health: Synergies between security and productivity. Geneva: International Labour Office.

16. International Labour Organization (2015). Occupational safety and health in the public service sector. Retrieved from https://www.ilo.org/global/topics/safety-and-health-at-work/industriessectors/WCMS_219031/lang--en/index.htm.

17. Kapetanidou, C. (2015). Occupational Issues - Hygiene and safety of employees (Part A). Athens: INE-GSEE Labour Institute [in Greek].

18. Koinoniko Polykentro of ADEDY (2012). Introductory Trade Union Education - The political and social context of trade union action - State, welfare state, public services and trade unionism. Athens: Koinoniko Polykentro of ADEDY [in Greek].

19. Koinoniko Polykentro of ADEDY (2013). The impact of restrictive policies on public services, public goods and public administration human resources. Athens: Koinoniko Polykentro of ADEDY [in Greek]. 
20. Lampousaki, S. (2013). Greece: Working conditions in central public administration. Dublin: Eurofound.

21. Lindholm, M., Reiman, A. \& Väyrynen. S. (2020). On future occupational safety and health challenges in industrialized countries - a systematic literature review. International Journal of Occupational and Environmental Safety, 4:1, 108-127.

22. Lupu, D. (2019). Cost-benefit analysis for transport infrastructure projects: Eastern european cases. Journal of Public Administration, Finance and Law, (15), 107-123.

23. Minister of Labour, Social Security and Social Solidarity (2017). Approval of the National Strategy for Health and Safety at Work for the years 2016-2020. Retrieved from http://www.et.gr/idocsnph/search/pdfViewerForm.html?args=5C7QrtC22wEsrjP0JAlxBXdtvSoCIrL8bReVM9NqpX_3U4LPcAS lceJInJ48_97uHrMts-

zFzeyCiBSQOpYnTy36MacmUFCx2ppFvBej56Mmc8Qdb8ZfRJqZnsIAdk8Lv_e6czmhEembNmZCMxL Mteg4qiK6queFJfXza5ZKd11w0E97FM7_RXZ_zBXpQd1c [in Greek].

24. Ministry of Health (2016). Response to yesterday's publication of EfSyn about individual contracts. Retrieved from https:/www.moh.gov.gr/articles/ministry/grafeio-typoy/press-releases/4088-apanthsh-sexthesino-dhmosieyma-ths-efsyn-gia-tis-atomikes-symbaseis [in Greek].

25. Ministry of Interior (n.d.). Circulars. Retrieved from https://www.ypes.gr/eguklioi/ [in Greek].

26. Ministry of Labour and Social Affairs (n.d.). Health and Safety at Work. Retrieved from https://ypergasias.gov.gr/ergasiakes-scheseis/ygeia-kai-asfaleia-stin-ergasia/ [in Greek].

27. Ministry of Labour and Social Affairs (2020). Establishment of a Working Group for the implementation of the institutional framework for health and safety at work in the public sector. Retrieved from

https://diavgeia.gov.gr/doc/\%CE\%A8\%CE\%97\%CE\%9B\%CE\%9F46\%CE\%9C\%CE\%A4\%CE\%9B\%CE \%9A-\%CE\%9D98?inline=true [in Greek].

28. Ministry of Labour, Social Security and Welfare (2014). Activity Report of the Labour Inspectorate Body for the year 2013. Athens: Labour Inspectorate Body [in Greek].

29. Nasios, G. (2020a). The multifaceted effects of the flexible employment policies and possible policies to address them. Social Policy, 12, 62-81[in Greek].

30. Nasios, G., (2020b). “The "Onset” of Flexible Forms of Employment in the Greek Public Sector: A Multidimensional Reform in the New Era”, HAPSc Policy Briefs Series, 1:2, 117-123. https://doi.org/10.12681/hapscpbs.26483

31. Safety \& Health Practitioner (2018). Public sector falls behind the private sector when it comes to health and safety. Retrieved from https://www.shponline.co.uk/occupational-health/public-sector-fallsbehind-the-private-sector-when-it-comes-to-health-and-safety/.

32. Schmidt L., Sjöström, J. and Antonsson, A. (2017). Understanding the Challenges Facing Occupational Health Services in the Swedish Public Sector. Nordic Journal of Working Life Studies, 7, 85104. DOI: https://doi.org/10.18291/njwls.v7i3.97090

33. Soumeli, E., (1998). Health and safety issues in the public sector. Retrieved from https://www.eurofound.europa.eu/publications/article/1998/health-and-safety-issues-in-the-public-sector

34. Stamati. A. \& Syriopoulos, P. (2013). Occupational Issues - Occupational Accident. Athens: INEGSEE Labour Institute [in Greek].

35. Supreme Administration of Civil Servants' Trade-Unions (2018). About the fatal accidents at work in the Local Government. Retrieved from https://adedy.gr/ergatika-dystiximata-ota/ [in Greek].

36. The Greek Ombudsman (2012). National Report 2011. Athens: The Greek Ombudsman [in Greek]. Creative Commons Attribution - Non Commercial - No Derivatives 4.0 International License. 